\title{
Information Transparency, Fairness and Labor Market Efficiency
}

\author{
Ebru Isgina ${ }^{\mathrm{a}, *}$, Barry Sopher ${ }^{\mathrm{b}}$ \\ ${ }^{a}$ Department of Economics and Finance, West Chester University of PA \\ 313 Anderson Hall, West Chester, PA 19383 \\ ${ }^{b}$ Department of Economics, Rutgers University \\ 209A New Jersey Hall, New Brunswick, NJ 08901
}

\begin{abstract}
The paper studies the role of information transparency on fairness concerns, welfare and efficiency. When the firm's productivity and ultimately profits are revealed, wage offers induce relatively fair divisions of potential gains and workers respond with higher performance. Workers respond not only to wages but also to firms' intentions concerning fairness. Information transparency serves as a mechanism that promotes fairness and performance while the lack of transparency results in reduced earnings for workers and market inefficiency.
\end{abstract}

Keywords: Experimental Economics, Incomplete Contracts, Fairness, Information Transparency

\section{Introduction}

This is an experimental study on information transparency and longterm employment relationships. The paper first asks specifically what types of fairness firms have in mind and workers respond to. Then it studies the impacts of information on firms' and workers' choices and on whether there

\footnotetext{
*Corresponding author

Email addresses: eisgin@wcupa.edu (Ebru Isgin), sopher@econ.rutgers.edu (Barry Sopher)
} 
are efficiency and welfare gains from information transparency.

The key finding is that transparency serves as an effective mechanism to improve both worker welfare and total market efficiency. When workers are fully informed about firms' productivity levels and potential profits, firms propose higher wages that represent fair divisions of total surplus. Workers respond to generous offers with high effort levels. However, workers' response is not constant and depends on the following factors. First of all, it is elevated with information transparency. That is, for given wages, workers provide more effort under full information. Secondly, it depends on whether a wage offer represents a fair share of the final surplus.

The definition of "fairness" is based on the behavioral and experimental paradigm by Ernst Fehr and his coauthors (Fehr and Schmidt, 1999 and Brown, Falk and Fehr, 2004 are some of the best known of this work). The models of fairness assume that there are fair-minded workers who adjust their behavior in the following manner: If the wage offer potentially represents an equal division of surplus, the fair-minded worker will react by supplying high effort to support that outcome. Otherwise, she will simply not be happy and reduce her effort. Thus, there is continuity in the worker's reaction to wage offers. Preferences for fairness do not imply blindly choosing the outcome where the surplus is split 50\%-50\%. Instead, these preferences are "focal", i.e the worker focuses on what the wage offer represents.

This paper contributes to the behavioral account of labor markets in a few different ways. First, the findings can explain the positive firm size- 
wage relationship, in line with much empirical evidence (e.g. Schmidt and Zimmermann, 1991). Second and most important, transparency promotes fairness and increases workers' effort, hence it increases the size of the total surplus and the average payoff for workers. Therefore, from the social planner's perspective, transparency should be desirable. Finally, the evidence here indicates that total welfare and efficiency can be increased if workers (or their unions) can convince firms to reveal information on profits.

\section{Experimental Approach to Labor Relationships}

Many theories based on fairness, inequity aversion and reciprocity have been offered to explain firm and worker behavior. Well documented evidence from laboratory and field experiments confirms the existence of behavioral motives in labor market decisions. However, the role of information transparency has yet to be explored in detail.

In this paper, we consider a setup which is applicable in a broad range of market scenarios. Firms and workers sign incomplete contracts and interact repeatedly. There are more workers than jobs, so that the competitive equilibrium prediction is for the wage to be at the opportunity cost of the workers. Likewise, there is no incentive, in a one shot game, for a worker to exert more than the minimum level of effort, because any additional effort only decreases the worker's share of the surplus (since his share is the fixed wage he has already accepted), while increased effort only increases the

firm's share. However, several facts stylized and empirical facts about labor 
relationships are at odds with this view. What is observed is that wages tend to be above the opportunity cost of workers, and effort levels tend to be increasing in the level of the wage offers. The interpretation usually given for this is that workers are concerned about the "fairness" of any given wage offer. This is the fairness version of the efficiency wage hypothesis (Akerlof, 1982, Akerlof and Yellen, 1990). Fairness is usually interpreted as "equal shares," which is a natural focal point in an experiment where roles are chosen randomly and there is no compelling reason why either side would be entitled to a larger share than the other.

The idea that workers respond to efficiency wages is well understood. According to the fair-wage effort hypothesis, workers compare wages with what they think is fair before making an effort choice. Models of reciprocity and inequity aversion explain deviations from standard labor market predictions (e.g. Fehr and Schmidt, 1999, Bolton and Ockenfels, 2000, Charness and Rabin, 2002, Dufwenberg and Kirschteiger, 2004). Meanwhile laboratory and field experiments largely support the claims of behavioral economic theory (e.g. Fehr et al. 1993, 1996, 1998). Concerns for fairness, trust and positive/negative reciprocity do exist in labor relationships and they significantly affect market outcomes.

It is established that preferences for fairness are present in labor relations and that fairness serves as an incentive mechanism for workers to perform well (see Fehr et al. 2008). The inequity aversion model by Fehr and Schmidt (1999) has been the framework for most experiments. The model is simply 
based on the idea that there are both selfish and fair-minded workers in the labor market. Fair-minded workers respond to generous offers with a generous effort level, thus firms have an incentive to offer rents even in oneshot interactions. But, the importance of fairness is amplified in repeated settings. Contractual incompleteness implies rewards and punishments in future periods and gives rise to "relational contracts" which are self-enforcing in nature (Macleod and Malcolmson, 1989). Since renegotiation and reputation become a concern, selfish workers have an incentive to mimic fair-minded workers and supply high effort when offered a generous wage. The presence of fair-minded workers also guarantee that greedy offers are penalized with low effort levels. Ultimately, the interaction between fairness concerns and repeated game incentives result in an outcome that involves non-minimal wage and effort and significant surplus sharing (Brown, Falk, Fehr, 2004).

The gift-exchange setup has been widely used to examine the performance effects of fairness (e.g. Hannan et al., 2002, Henning-Schmidt et al., 2003, Brandts and Charness, 2004). In a typical gift exchange experiment, the ordering of events is as follows. The firm proposes a fixed wage to be paid, but does not enforce worker performance. Then the worker chooses an effort level which determines her and the firm's final payoffs. In this paper, we extend this paradigm in a couple more directions. First, we focus on longterm contracting by allowing employers to make offers to specific workers in a private fashion (similar to Brown, Falk, Fehr, 2004). Second, we introduce heterogeneity in the following sense: firms have multiple jobs with different 
productivity levels, i.e. at given effort levels some jobs are more productive or more profitable than others. Third and most important, we introduce the following information problem to the design: when the market is completely transparent, workers are fully informed about the exact productivity of their jobs, thus, they know the size of potential final surplus and profits for their firms before making an effort decision; however, in the absence of transparency, workers are left in the dark about the total surplus created as a result of their efforts.

The difference between these two hypothetical states (full information and limited information) summarizes the role of information on employment relations, fairness and efficiency. It is almost impossible to find field data that fits into this ideal setup. However, experimental methods permit exogenous variations in the information structure.

\section{Experiment Design}

A total of 52 subjects participated in 4 sessions and interacted 646 times. Each session included 18 periods with 3 employers and 10 workers. The sessions were conducted in Gregory Wachtler Experimental Economics Laboratory. Subjects were seated in cubicles with computers connected to each other by z-Tree experimental software (Fischbacher, 2007). A typical session took an hour and a half and the average payment was approximately $\$ 20$.

In a given session, 3 participants were assigned the role of an individual firm and 10 were assigned the role of a worker; these roles remained the same 
throughout the session. The program assigned each firm and each worker an identification number which was fixed throughout the session. Thus, workers were able to recognize each firm and vice-versa in all future periods, thus allowing renegotiation.

This setup, with repeated interactions, was adapted from Brown, Falk and Fehr (2004). Then it was modified in the following ways to study information effects.

Each firm had three jobs with different productivity levels. The productivity coefficient, $p$, could take three different values: 10, 8 or 6 for high, medium or low productivity respectively.

Each firm could make multiple offers but was allowed to hire only one worker for each job. The offers included a wage to be paid, w, and a nonbinding desired effort level, $\tilde{e}(w \in\{0,1, \ldots, 100\}$ and $\tilde{e} \in\{1,2, \ldots, 10\})$.

Each firm had the option of submitting private and/or public offers. Public offers were known to and could be accepted by all workers. Private offers were known by and directed to specific workers.

Each worker could accept or reject offers. If a worker accepted an offer, she chose her actual effort level (e), and thus determining her final payoff. The payoffs were calculated in experimental currency units.

The firm's profit after each trade was $\pi_{f}=p e-w$, where $p$ is the productivity coefficient.

The worker's payoff conditional on employment was $\pi_{i}=w-c(e)$ where $c(e)$ is the cost of effort. The cost schedule is given in Table 1 . The firms were 
Table 1: Cost of Effort

\begin{tabular}{lcccccccccc}
\hline \hline Effort level & 1 & 2 & 3 & 4 & 5 & 6 & 7 & 8 & 9 & 10 \\
Cost of effort c(e) & 0 & 2 & 4 & 5 & 7 & 8 & 10 & 12 & 15 & 18 \\
\hline \hline
\end{tabular}

informed about the cost function c(e), which was the same for all workers.

There was involuntary unemployment every period since there were 10 workers but 9 job openings. If a worker failed to find a job, she was paid an unemployment benefit of 5 experimental currency units.

When the next period started all workers and firms could renew contracts or find different matches. Firms and workers used the same ID numbers throughout the sessions, so that they could find (or avoid) each other in every subsequent session.

Two treatments were designed in order to analyze how information affects wage profiles and performance. In the Full Information Treatment (FULL), the firm told workers the productivity level as part of its job offer. Workers could observe the productivity of each job. In the Limited Information Treatment (LIM), the employers were privately informed about the productivity levels at the beginning of each period, but this information was not revealed to the workers.

\section{Findings}

Table 2 summarizes the aggregate data on limited and full information sessions. Full information extracts higher wages and effort levels compared 
Table 2: Descriptive Statistics I

\begin{tabular}{lrlrl}
\hline \hline & \multicolumn{2}{c}{ Limited Information } & \multicolumn{2}{c}{ Full Information } \\
\hline Wage & 21.96 & $(0.72)$ & 33.73 & $(0.90)$ \\
Effort & 5.08 & $(0.16)$ & 6.95 & $(0.18)$ \\
Worker's Payoff & 15.92 & $(0.54)$ & 23.98 & $(0.63)$ \\
Firm's Payoff & 20.29 & $(1.24)$ & 21.28 & $(1.11)$ \\
Total Surplus & 36.21 & $(1.31)$ & 45.26 & $(1.38)$ \\
Efficiency & $58 \%$ & & $73 \%$ & \\
N & 324 & & 322 & \\
\hline \hline
\end{tabular}

Standard deviations are in parentheses.

to limited information. The firms are left with comparable profits regardless of the availability of information while the workers are clearly better off. The size of the total surplus and workers' payoffs are significantly higher with full information. Optimal effort level that maximizes social surplus at 62 experimental currency units is $10.73 \%$ of maximum efficiency is gained under transparency while it is only $58 \%$ under the lack of transparency.

Table 3 suggests that the payoff distribution between workers and firms is close to being equal with full information, especially for medium and high productivity jobs. The transparency seems to work to the firm's benefit if the job is of low productivity, but it works against the firm if the job is of high productivity.

\subsection{Private Offers and Contract Renewal}

Private offers allow for renegotiation and contract renewal. The main instrument to engage in relational contracts was the option of sending private 
Table 3: Descriptive Statistics II

\begin{tabular}{lrlll}
\hline \hline & \multicolumn{3}{c}{ Limited Information } & \multicolumn{2}{c}{ Full Information } \\
\hline Low Productivity & & & & \\
Worker's Payoff & 12.25 & $(0.82)$ & 18.21 & $(0.88)$ \\
Firm's Payoff & 6.70 & $(1.25)$ & 13.37 & $(1.34)$ \\
Medium Productivity & & & & \\
Worker's Payoff & 14.27 & $(0.86)$ & 20.90 & $(0.74)$ \\
Firm's Payoff & 19.90 & $(1.90)$ & 19.24 & $(1.36)$ \\
High Productivity & & & & \\
Worker's Payoff & 23.25 & $(0.92)$ & 30.85 & $(1.22)$ \\
Firm's Payoff & 34.94 & $(2.25)$ & 29.25 & $(2.07)$ \\
\hline \hline
\end{tabular}

Standard deviations are in parentheses.

offers. Figure 1 shows that the percentage of private offers increases over time regardless of whether the regime is limited information or full information. Moreover, the majority of offers made in private were aimed at contract renewal according to Figure 2.

(Figures 1-2)

The use of private offers suggests that firms are interested in forming long-term relations. Information does not seem to have a particular impact on contract renewal as the firms want to hold onto productive relationships in any case.

Table 4 represents the decision to renew contracts. The likelihood of renewal mainly increases with reputation. Reputation of a worker, from the perspective of the firm, was measured as the worker's performance in their last encounter. On the other hand, the productivity level does not help to 
Table 4: Contract Renewal

\begin{tabular}{lclcc}
\hline \hline & \multicolumn{2}{c}{ Limited Information } & \multicolumn{2}{c}{ Full Information } \\
\hline Reputation & $0.09^{* * *}$ & $(0.01)$ & 0.08 & $(0.09)$ \\
Medium productivity & 0.02 & $(0.05)$ & -0.01 & $(0.02)$ \\
High productivity & -0.02 & $(0.05)$ & 0.01 & $(0.05)$ \\
Constant & $0.14^{* * *}$ & $(0.01)$ & $0.19^{* * *}$ & $(0.05)$ \\
\hline \hline
\end{tabular}

Random-effects Probit. $\chi^{2}(3)=48.66$ for 'Limited Information' and $\chi^{2}(3)=64.04$ for 'Full Information'.

Clustered robust standard errors in parentheses. $* * *: p<0.01, * *$ : $p<0.05$

explain contract renewal.

\subsection{Firms}

While initially wages are around the same, the impact of information becomes clear later on. Figure 3 shows that average wage offers are consistently higher under information transparency.

\section{(Figure 3)}

Table 5 shows the results of the wage regression. Good reputation motivates generous wages. Likewise, private wage offers are greater than publicly made ones. The job characteristics are significant in explaining the wage decision; i.e. offers increase with the productivity level. There are withinfirm wage differences in both sessions; however the difference is more defined when full information is enforced. Firms significantly separate wage offers. Limited information on the other hand results in weak separation of payoffs among co-workers; while both significantly greater than zero, coefficients for 
Table 5: Dependent Variable-Wage

\begin{tabular}{lcccc}
\hline \hline & \multicolumn{2}{c}{ Limited Information } & \multicolumn{2}{c}{ Full Information } \\
\hline Reputation & $0.68^{* * *}$ & $(0.30)$ & $1.44^{* * *}$ & $(0.12)$ \\
Private Offer & $4.54^{* * *}$ & $(1.76)$ & $8.92^{* *}$ & $(4.20)$ \\
Medium productivity & $6.65^{* * *}$ & $(1.18)$ & $3.28^{* * *}$ & $(1.17)$ \\
High productivity & $7.38^{* * *}$ & $(3.03)$ & $10.52^{* * *}$ & $(1.71)$ \\
Constant & $16.44^{* * *}$ & $(2.75)$ & $20.30^{* * *}$ & $(3.13)$ \\
\hline \hline
\end{tabular}

Random-effects GLS. $\chi^{2}(4)=217.74$ for 'Limited Information' and $\chi^{2}(4)=499.14$ for 'Full Information'.

Clustered robust standard errors in parentheses. $* * *: p<0.01, * *$ : $p<0.05$

medium and high productivity job offers in the limited information regime are not statistically different from each other.

\subsection{Workers}

Effort provision not only determines final payoffs but also potentially affects the length of the relationship. Figure 4 depicts the evolution of average wages over time. The first thing to notice is that the average effort is higher in full information sessions.

(Figure 4)

Table 6 shows the results of the random-effects ordered probit estimation of effort. Not surprisingly the effort choice depends significantly on the wage offer. But there are two very interesting observations in Table 6. The first one is that wages extract more effort under full information. The availability of information just by itself seems to be important for worker's performance. 
Table 6: Dependent Variable-Effort

\begin{tabular}{lclcl}
\hline \hline & \multicolumn{2}{c}{ Limited Information } & \multicolumn{2}{c}{ Full Information } \\
\hline Wage & $0.09^{* * *}$ & $(0.02)$ & & \\
Wage*low productivity & & & $0.16^{* * *}$ & $(0.01)$ \\
Wage*medium productivity & & & $0.14^{* * *}$ & $(0.01)$ \\
Wage*high productivity & & & $0.12^{* * *}$ & $(0.00)$ \\
Desired effort & $0.32^{* * *}$ & $(0.11)$ & $0.25^{* * *}$ & $(0.08)$ \\
Last Period & $-2.97^{* * *}$ & $(0.68)$ & $-2.60^{* * *}$ & $(0.45)$ \\
Constant & $1.05^{* *}$ & $(0.37)$ & $1.70^{* *}$ & $(0.47)$ \\
\hline \hline
\end{tabular}

Random-effects Ordered Probit. $\chi^{2}(3)=238.56$ for 'Limited Information' and $\chi^{2}(5)=352.98$ for 'Full Information'.

Clustered robust standard errors in parentheses. $* * *: p<0.01, * *$ : $p<0.05$

Secondly, the marginal effect of a wage offer is higher for low productivity jobs. That is, the workers do take into account that a dollar increase in wages represents a greater share of the total surplus if the job is of low productivity. Information transparency naturally improves relations between parties, while the lack of transparency reduces reciprocity by workers.

Desired effort is significant in explaining effort as well. Compliance with the firm's expectations must be an enforcement mechanism for higher performance and long lasting relations. This could also be considered as a simple form of cheap talk. The probability to work harder increases upon contract renewal too.

\subsection{Fairness and Efficiency}

Figure 5 shows that average firm profit is more or less the same regardless of the information structure. Figure 6 confirms that firms end up with 
Table 7: Firm's Share

\begin{tabular}{lllll}
\hline \hline & \multicolumn{2}{c}{ Limited Information } & \multicolumn{2}{c}{ Full Information } \\
\hline Medium productivity & $0.85^{* *}$ & $(0.14)$ & $0.65^{* *}$ & $(0.16)$ \\
High productivity & $0.77^{* * *}$ & $(0.13)$ & $0.62^{* * *}$ & $(0.16)$ \\
Last Period & $-0.90^{* *}$ & $(0.19)$ & $-1.02^{* *}$ & $(0.39)$ \\
Constant & -0.25 & $(0.16)$ & 0.06 & $(0.09)$ \\
\hline \hline
\end{tabular}

Random-effects GLS. $\chi^{2}(3)=58.26$ for 'Limited Information' and $\chi^{2}(3)=66.68$ for 'Full Information'.

Clustered robust standard errors in parentheses. $* * *: p<0.01, * *$ : $p<0.05$

about half of the total surplus under full information, whereas their shares are larger when the workers are not informed. The finding is documented in Table 7 as well. The outcome under transparency reveals the emphasis on fairness preferences. Firms keep smaller shares of surplus although that does not mean they are worse off. Limited information dampens fairness incentives and leaves firms with higher shares without improving total gains. Finally total surplus is depicted in Figure 7 across limited and full information sessions where the difference between treatments is statistically significant.

(Figures 5-7)

\section{Conclusion}

Fairness concerns shape employment relationships significantly. Theories that model social preferences are based on the assumption that people with 
fairness preferences reduce own payoffs to avoid unfair outcomes or punish unfair behavior. The existence of fair-minded people in the market increases wages and effort levels above the market clearing levels both in one shot and repeated interactions. Effort increases with wage but this effect is amplified in repeated settings due to renegotiation and reputation formation. Experimental research on employment relationships has shown that fairness is an incentive mechanism for workers to perform well and firms to offer rents to their workers. The contribution of this paper is on the role of information on workers' and firms' choices and on whether there are efficiency and welfare gains from information transparency.

The findings of this paper suggest that information affects the market outcome in significant ways. Information transparency on firms' profits motivates firms to offer higher wages which induce a relatively more fair distribution of payoffs and workers respond to wage increases by increasing effort. Most importantly, workers' response is elevated with information transparency. That is, for given wages, workers provide more effort under full information. The availability of information just by itself might have a positive psychological effect on worker's choice. The evidence is hard to explain with existing theories, and requires further research. Furthermore, workers respond to firms' intentions about how to share the potential final surplus. A dollar increase implies a larger share of surplus if the job has low productivity. The evidence shows that the marginal effect of a wage increase is slightly higher for lower productivity jobs. 
Under full information, wage offers are higher and firms separate offers across different jobs, i.e. high wages are offered for high productivity jobs, that result in equal division of total surplus. Workers reciprocate to these offers by exerting more effort, thus increasing gains from interaction. On the other hand, wages are lower and more compressed when workers are left in the dark. Since firms have an incentive to pretend that their jobs have low productivity, workers do not choose high effort levels to increase firms' payoffs. In the end, workers' payoffs are reduced and firms collect a larger of the surplus which is now lower in the absence of information transparency.

Transparency promotes preferences for fairness and increases workers' effort, hence it increases the size of the total surplus and the average payoff for workers. Therefore, from the social planner's perspective, transparency should be desirable. Finally, the evidence here indicates that total welfare and efficiency can be increased if workers (or their unions) can convince firms to reveal information on profits.

The experiment is convenient for addressing some further questions. Although the findings from this specific experiment suggest that firms are not hurt by full information, it is still a question whether firms would want to reveal productivity information if they were given the option. Another question is whether the unemployment rate (which was constant in the experiment) changes the impact of information transparency. Concerns for fairness and the extent that it motivates performance are subject to question under various rates of unemployment. 


\section{Figures}




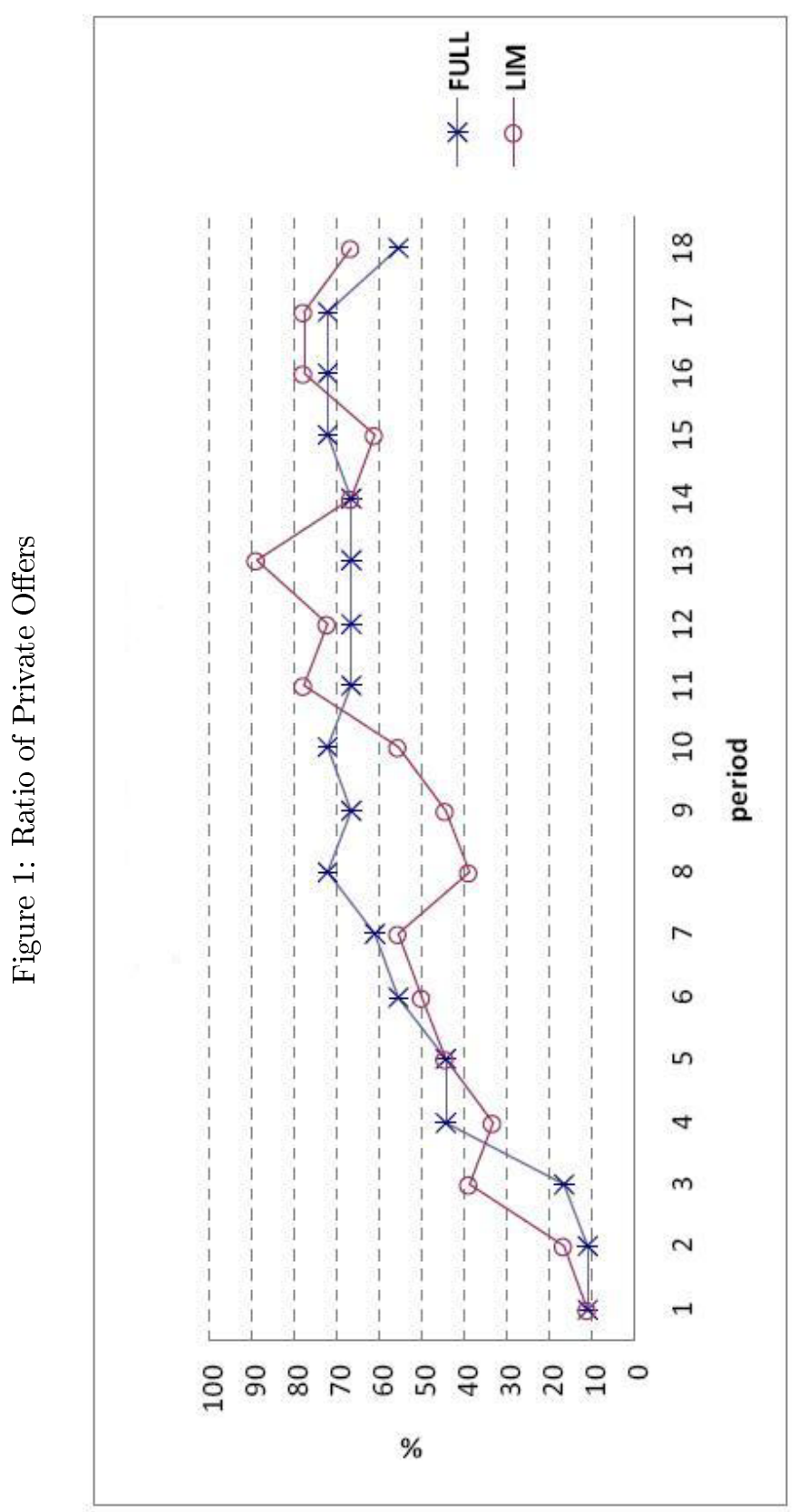




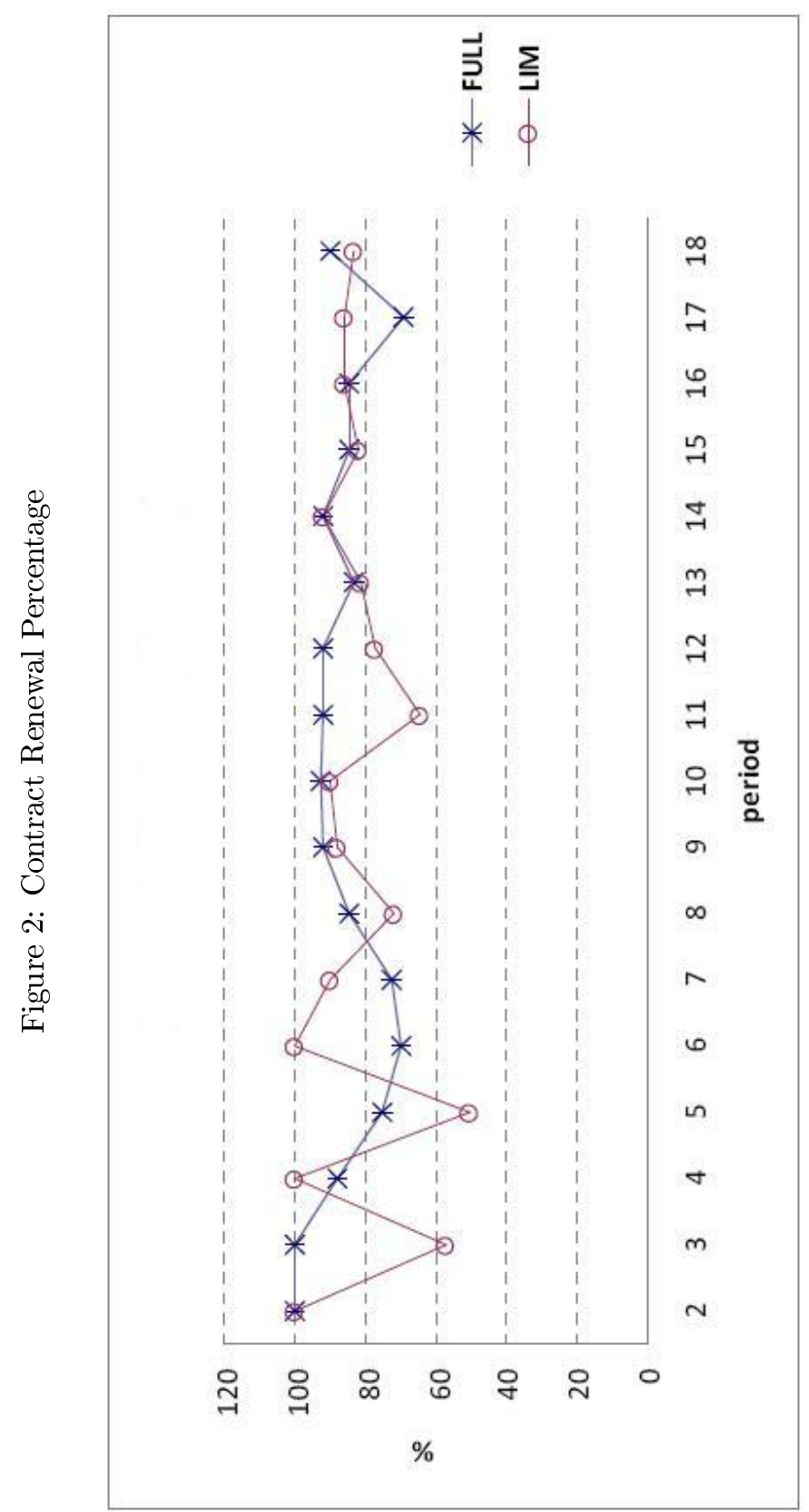




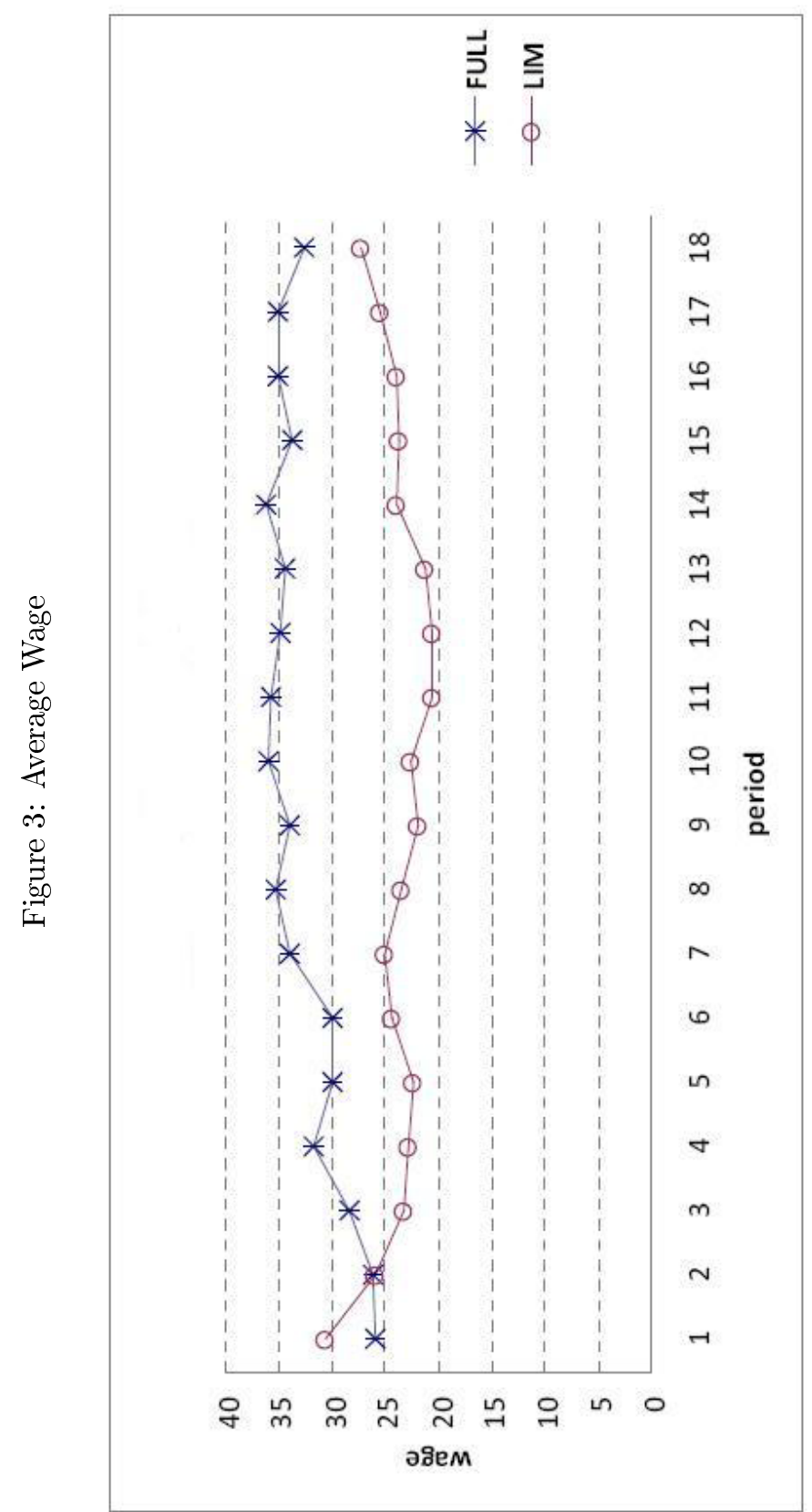




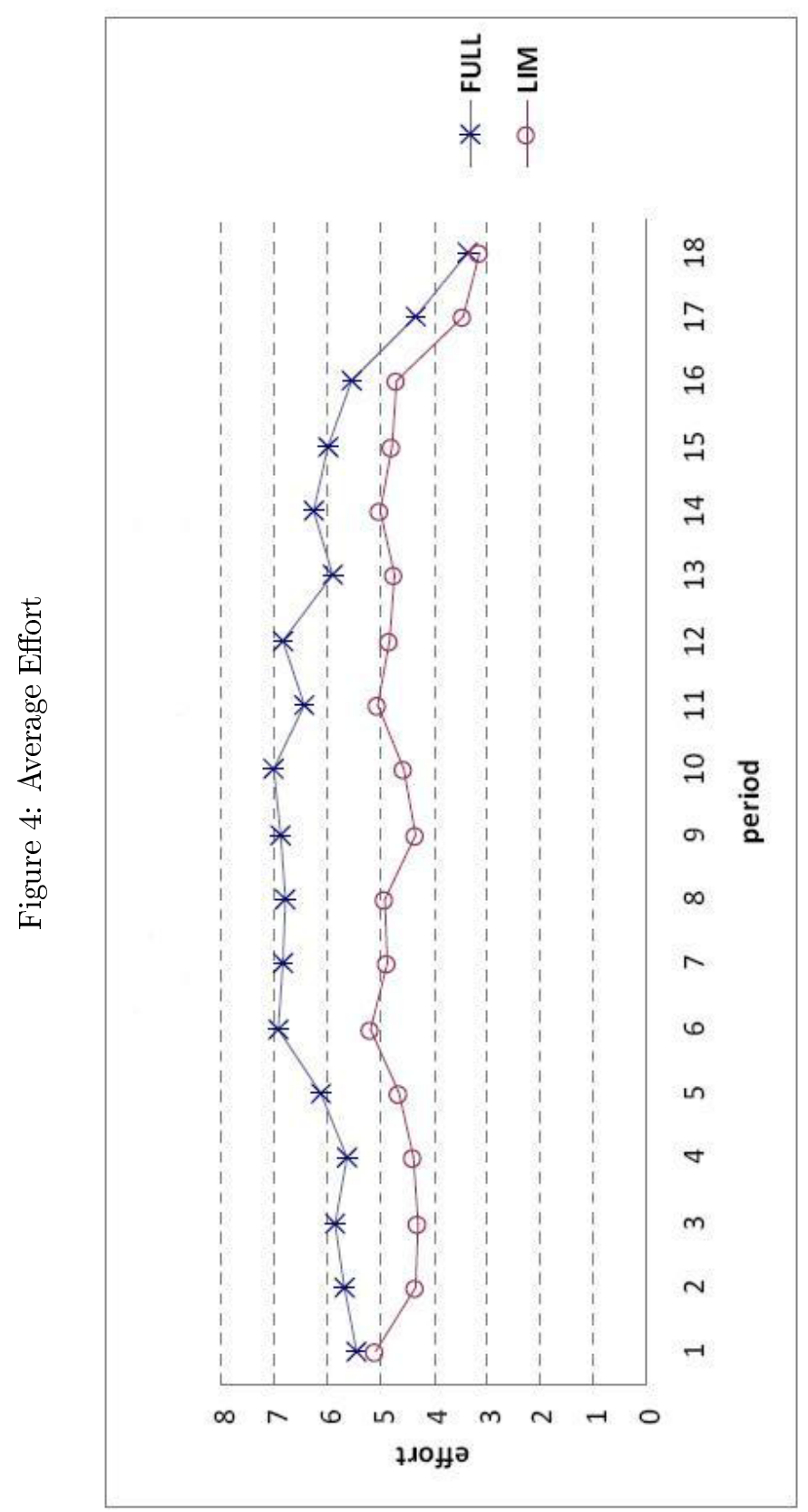




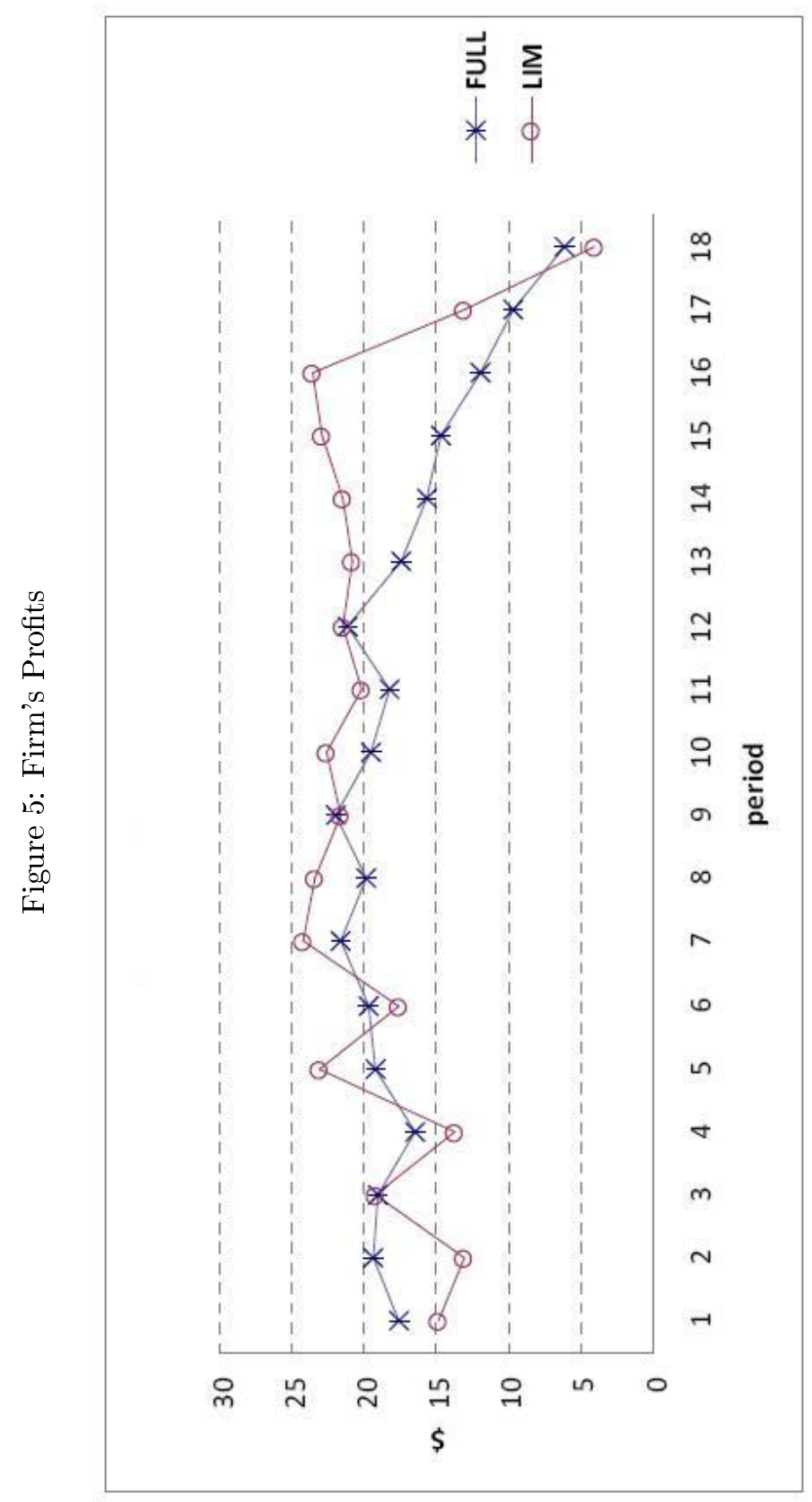




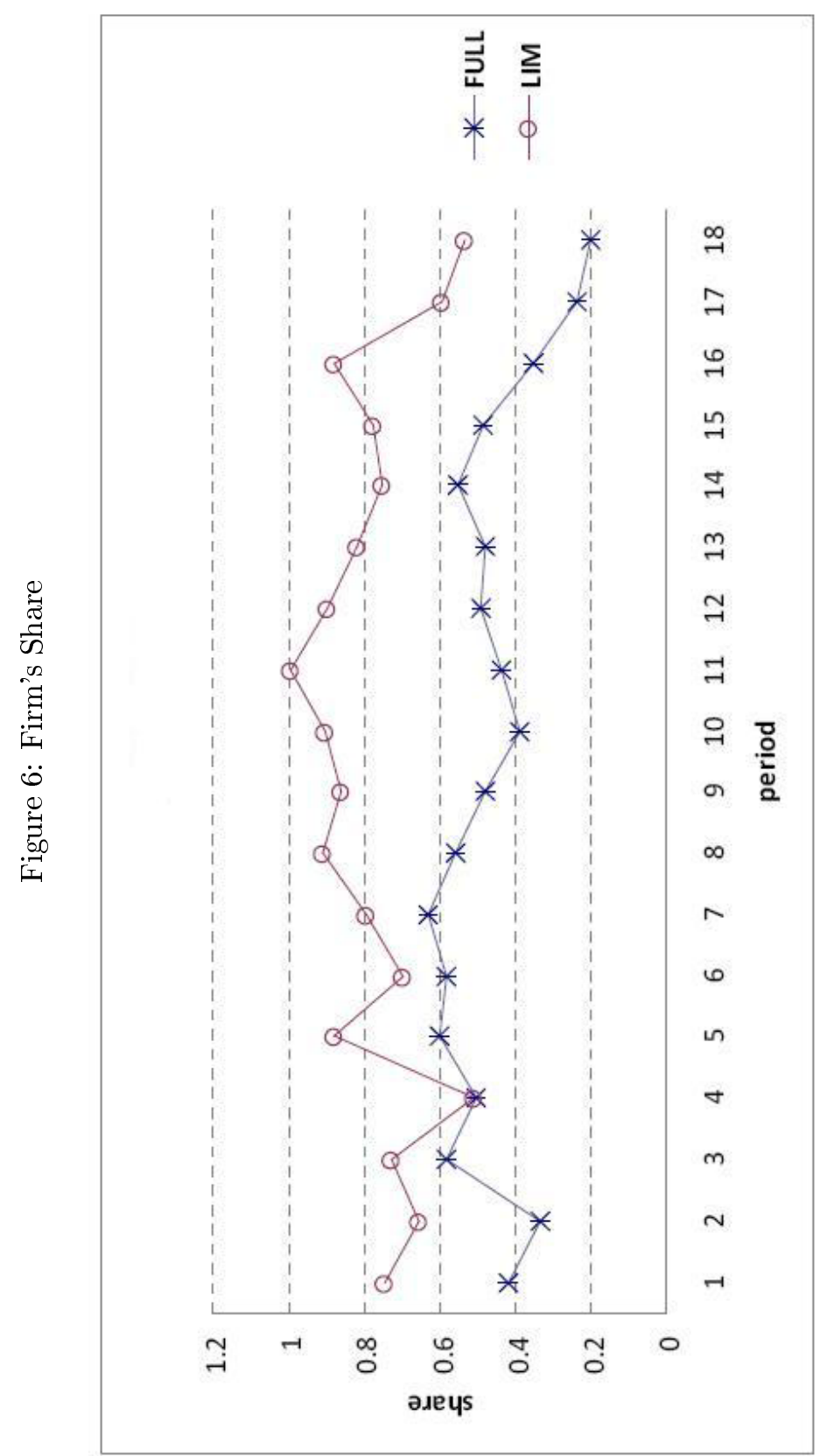




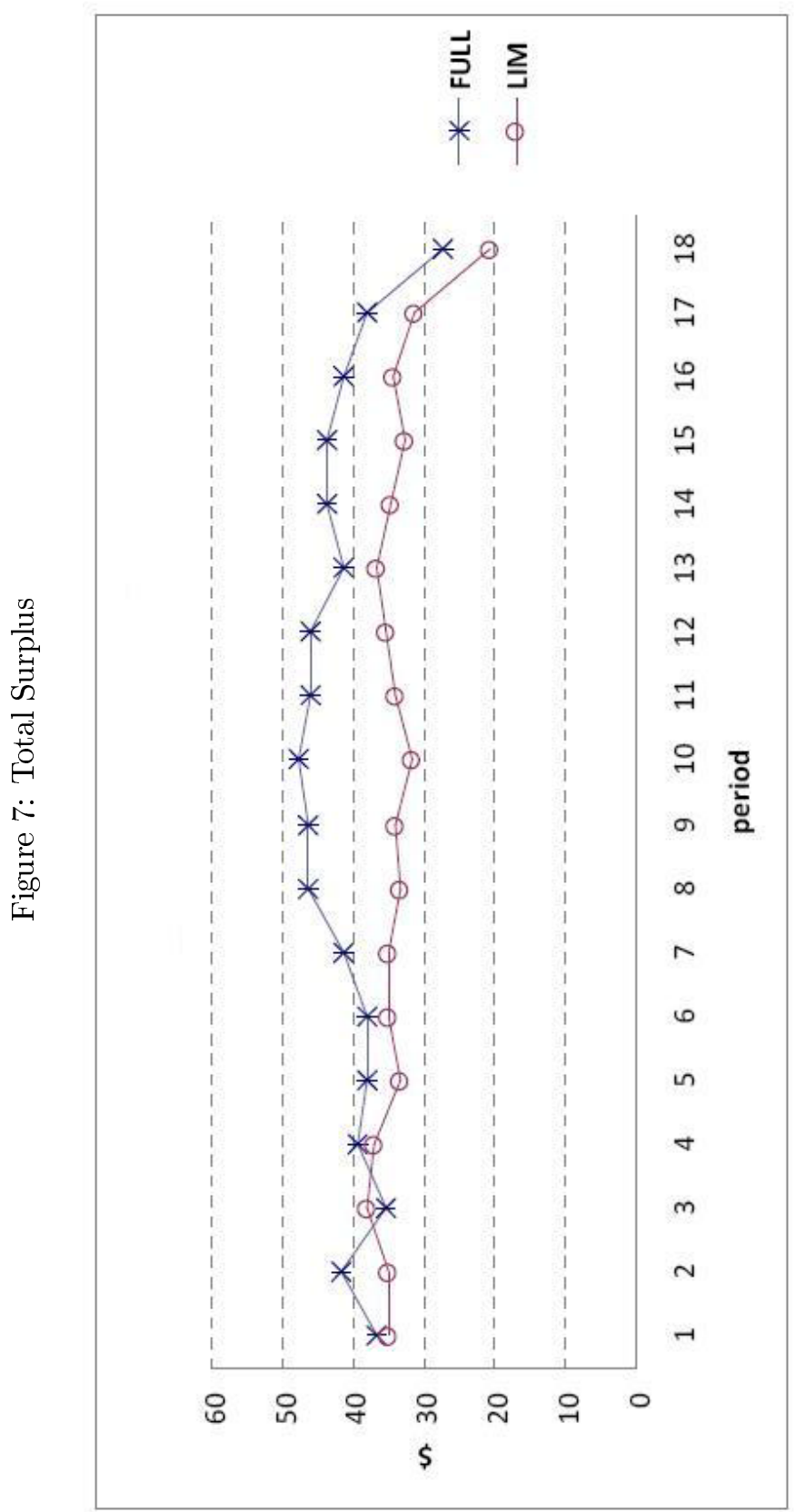




\section{Acknowledgement}

The authors thank W. Bentley Macleod for valuable discussions.

\section{References}

[1] Akerlof, G. A. (1982). Labor contracts as partial gift exchange. The Quarterly Journal of Economics, 97(4), 543-569.

[2] Akerlof, G. A., \& Yellen, J. L. (1990). The fair wage-effort hypothesis and unemployment. The Quarterly Journal of Economics, 105(2), 255283.

[3] Brandts, J., and G. Charness, "Do Labor Market Conditions Affect Gift Exchange? Some Experimental Evidence", The Economic Journal, 2004.

[4] Brown, M., Falk, A., \& Fehr, E. (2004). Relational contracts and the nature of market interactions. Econometrica, 72(3), 747-780.

[5] Charness, G., \& Rabin, M. (2002). Understanding social preferences with simple tests. The Quarterly Journal of Economics, 117(3), 817-869.

[6] Dufwenberg, M., \& Kirchsteiger, G. (2004). A theory of sequential reciprocity. Games and Economic Behavior, 47(2), 268-298.

[7] Falk, A., Fehr, E., \& Fischbacher, U. (2008). Testing theories of fairness: Intentions matter. Games and Economic Behavior, 62(1), 287-303. 
[8] Fehr, E., Kirchsteiger, G., \& Riedl, A. (1993). Does fairness prevent market clearing? An experimental investigation. The Quarterly Journal of Economics, 108(2), 437-459.

[9] Fehr, E., Kirchsteiger, G., \& Riedl, A. (1996). Involuntary unemployment and non-compensating wage differentials in an experimental labour market. The Economic Journal, 106-121.

[10] Fehr, E., Brown, M., \& Zehnder, C. (2009). On reputation: A microfoundation of contract enforcement and price rigidity*. The Economic Journal, 119(536), 333-353.

[11] Fehr, E., \& Schmidt, K. M. (1999). A theory of fairness, competition, and cooperation. The quarterly journal of economics, 114(3), 817-868.

[12] Fehr, E., \& Schmidt, K. M. (2000). Fairness, incentives, and contractual choices. European Economic Review, 44(4), 1057-1068.

[13] Fehr, E., Goette, L., \& Zehnder, C. (2008). A behavioral account of the labor market: The role of fairness concerns. Institute for Empirical Research in Economics, University of Zurich, Working Paper, (394).

[14] Fischbacher, U., "z-Tree: Zurich Toolbox for Ready-made Economic Experiments", Experimental Economics, 2007

[15] Hannan, R. L., Kagel, J. H., \& Moser, D. V. (2002). Partial Gift Exchange in an Experimental Labor Market: Impact of Subject Population 
Differences, Productivity Differences, and Effort Requests on Behavior*. Journal of Labor Economics, 20(4), 923-951.

[16] Henning-Schmidt, H., Rockenbach, B., \& Sadrieh, A. (2003). Incomplete and asymmetric surplus information in labor relations.

[17] MacLeod, W. B., \& Malcomson, J. M. (1989). Implicit contracts, incentive compatibility, and involuntary unemployment. Econometrica: Journal of the Econometric Society, 447-480.

[18] Schmidt, C. M., \& Zimmermann, K. F. (1991). Work characteristics, firm size and wages. The Review of Economics and Statistics, 705-710. 